\section{EMBnet Annual General Meeting - Publicity and Public Relations Project Committee report}
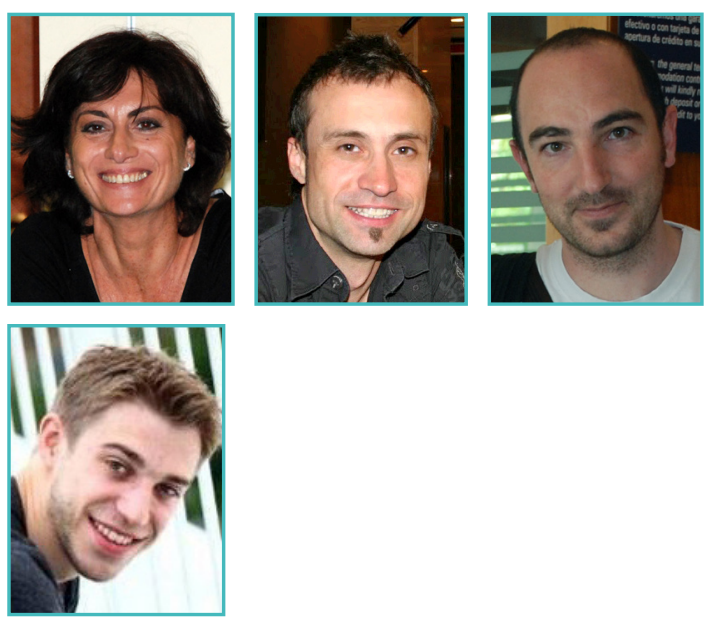

\section{Domenica D’Elia' ${ }^{\bowtie}$, Lubos Klucar², Rafael Jimenez ${ }^{3}$, Axel Thieffry ${ }^{4}$}

'CNR, Institute for Biomedical Technologies, Bari, Italy ${ }^{2}$ Institute of Molecular Biology, Slovak Academy of Sciences, Slovakia

${ }^{3}$ ELIXIR Chief Technical Officer - ELIXIR directorate, Hinxton, Cambridge, United Kingdom

${ }^{4}$ Section for Computational and RNA Biology \& Biotech Research and Innovation Center (BRIC), Department of Biology, University of Copenhagen, Denmark

Received 1 December 2015; Published 21 December 2015

D’Elia D et al. (2015) EMBnet.journal 21, e857. http:!//dx.doị. org/10.14806/ej.21.0.857

This report provides a short summary of the work and achievements of the EMBnet Publicity and Public Relations Project Committee (P\&PR PC) from June 2014 to May 2015. In particular, we give a brief overview of our activities, whose priorities were agreed according to the needs and requests both of the Executive Board (EB) and of the EMBnet community.

The main focal points were: i) management of the EMBnet website and content moderation; ii) coordination and monthly drafting, release and advertisement of EMBnet.digest; iii) assistance in the production and release of new EMBnet QuickGuides; iv) support in the production and advertisement of EMBnet.journal; v) management of relationships within EMBnet's communities and related networks/societies; vi) support in the organisation of the 2015 EMBnet AGM and of a series of workshops and tutorial events, mostly relating to EMBnet members' involvement in affiliated projects.

We also managed EMBnet sponsorships of large conferences, such as the SAGS-SASBi Joint Congress', held on 23-26 September 2014 in Kwalata Game Ranch (ZA), and the Joint NETTABIB 2014 Workshop 2 , Turin (IT), 15-17 October 2014. The P\&PR PC produced for the SAGS-SASBi Joint Congress a new EMBnet presentation, given by Alan Christoffels, and new promotional material that was included in the conference pack. Judit Kumuthini was responsible for the EMBnet exhibition desk. EMBnet received acknowledgement, had its logo on all printed and digital conference material and in the SAGS/SASBi website. As for the NETTAB-IB workshop, the Chair of the P\&PR $P C$ participated in the workshop, presented the EMBnet poster, and gave a 5-minute presentation of EMBnet and its membership benefits. The EMBnet leaflet and a leaflet on EMBnet membership were distributed to participants (about 130 researchers from Italy and many other European countries). A snapshot of the new EMBnet presentation is shown in Figure 1.

The P\&PR PC had regular meetings, although their frequency was lowered at the beginning of the New Year, owing to some drastic changes, such as the sudden stalling of our plans to organise the 2015 AGM in Serbia, following the resignation of a member of the EB. These events partially froze new initiatives that the P\&PR PC had planned for the year, but did not prevent us from accomplishing our normal duties and tasks. This year, the PR\&PR PC has supported the $\mathrm{EB}$ and the EMBnet community with the release of 12 EMBnet.digests ${ }^{3}$, the publication of four new QuickGuides ${ }^{4}$ and of EMBnet.journal Vol. 20 (2014 release) ${ }^{5}$ and the journal Supplement $\mathrm{A}^{6}$, on the conference "NGS Data after the Gold Rush - COST Action BM1006", held in Norwich (UK), 6-8 May 2014.

We assisted EMBnet members with any type of support requested; managed and answered contacts' requests posted in our website; informed the community about job opportuni-

\footnotetext{
www.sasbi-sags2014.org.za/

www.igst.it/nettab/2014/

www.embnet.org/embnet-digest

www.embnet.org/embnet-quickguides

journal.embnet.org/index.php/embnetjournal/issue/ view/77

6 journal.embnet.org/index.php/embnetjournal/issue/ view/79/showToc
} 


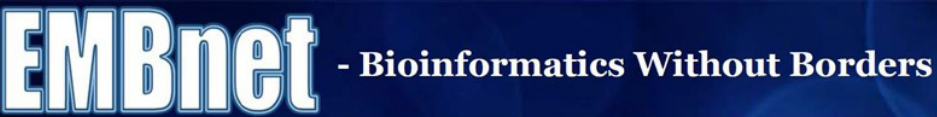

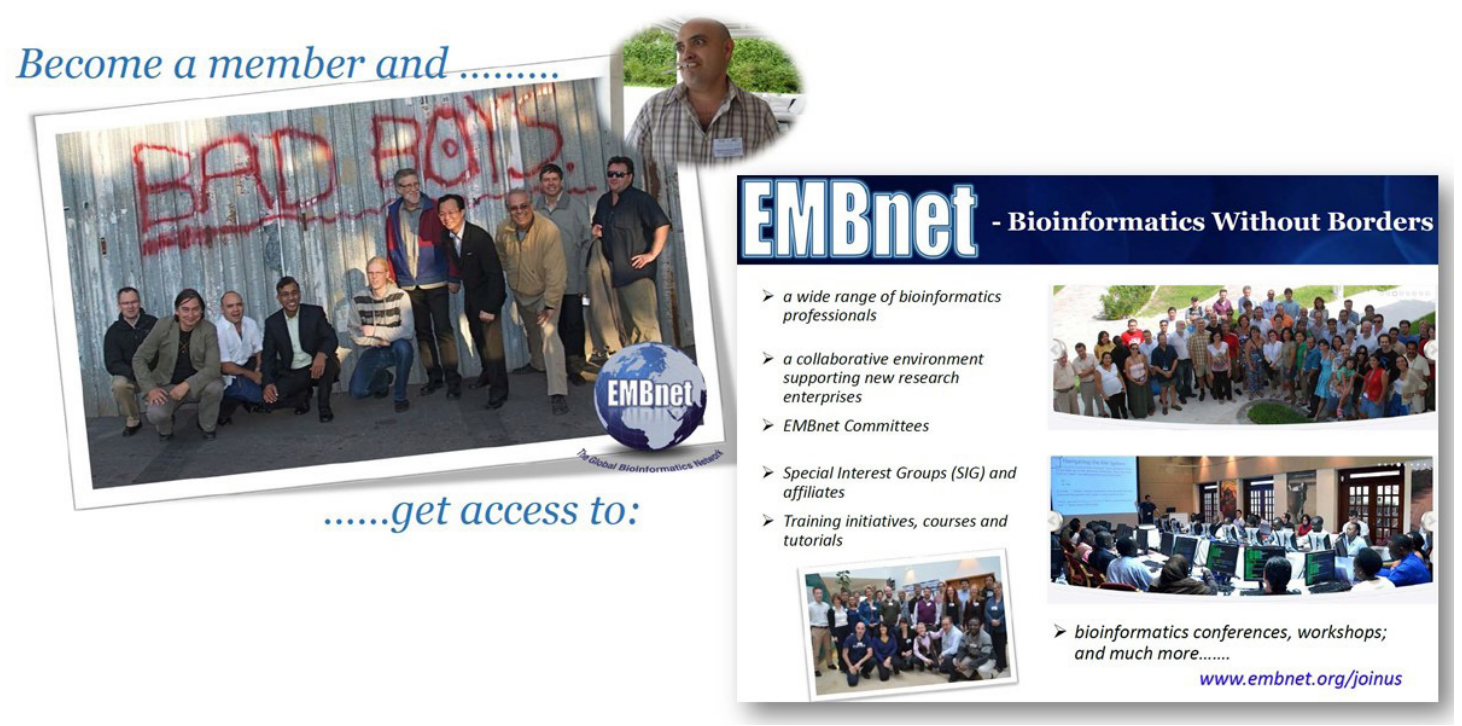

Figure 1. Snapshot (two slides) of the EMBnet presentation, re-designed in 2014 by the P\&PR PC.

ties, EMBnet.digest and EMBnet.journal releases in a timely fashion, and advertised them on the EMBnet website ${ }^{7}$ and in the Linkedln EMBnet Group 8 .

The Chair of the PC attended all Operational Board (OB) and EMBnet virtual general meetings, and collaborated in the activities of the $\mathrm{OB}$ in order to support the EB in guiding EMBnet toward the objectives agreed with the Board at the 2014 AGM, hosted in Lyon (FR), 26-30 May (Attwood, 2014).

A complete and exhaustive summary of EMBnet's achievements from June 2014 to May 2015 , and to which the P\&PR PC is proud to have contributed, is provided by the EB in the related article by Attwood et al., "2015 Annual General Meeting - Executive Board Report"', in this issue.

\section{Acknowledgements}

The Chair of the P\&PR PC personally thanks all the Committee's members; without their support, many of the activities and achievements reported above would have been impossible to realise. In particular, special thanks go to Axel Thieffry for his effective and enthusiastic contribution. Finally, and as always, I would like to thank the EB, which has continually supported the P\&PR $\mathrm{PC}$ with great effectiveness.

\section{References}

Attwood TK (2014) EMBnet, the Global Bioinformatics Network: a report on the workshop and 26th AGM, Lyon, May 2014. EMBnet.journal 20, e786. http:-//dx. dọi.org/10.14806/ej.20.0. 786

Chair: Domenica D'Elia

Secretary: Lubos Klucar;

Member: Axel Thieffry and Rafael Jimenez

3 June, 2015

www.embnet.org/

8 www.linkedin.com/groups/922107

9 journal.embnet.org/index.php/embnetjournal/article/ view/855 